\title{
Knowledge management in business and education: Evidence from Vietnam companies and uni- versities
}

\author{
Ngoc Xuan $V u^{a^{*}}$
}

${ }^{a}$ Faculty of Economics, National Economics University, Vietnam

\begin{tabular}{|c|c|}
\hline C H R O N I C L E & A B S T RA C T \\
\hline $\begin{array}{l}\text { Article history: } \\
\text { Received: June 4, } 2019 \\
\text { Received in revised format: June } \\
272019 \\
\text { Accepted: June } 29,2019 \\
\text { Available online: } \\
\text { June } 29,2019 \\
\text { Keywords: } \\
\text { Knowledge management (KM) } \\
\text { Organizational culture (OC) } \\
\text { Knowledge sharing (KS) } \\
\text { Knowledge exchange (KE) } \\
\text { Information technology (IT) }\end{array}$ & $\begin{array}{l}\text { Knowledge Management (KM) is the process of system identification, acquisition and transfer of } \\
\text { information and knowledge that people can use to create for perfect competition. KM is considered } \\
\text { as an intellectual property of opinions in favour of social orientation and it is created in organiza- } \\
\text { tions through social relationships. The definition of KM highlights that it could be considered as } \\
\text { closely related to the theory and practice, and is a highly interdisciplinary field of multi-discipli- } \\
\text { nary. The purpose of this paper is associated with the knowledge management in general and uses } \\
\text { survey in Vietnam companies and universities to analysis the role of knowledge management for } \\
\text { business development. The authors collected data from } 300 \text { companies and universities in Hanoi, } \\
\text { Danang, Ho ChiMinh and Can Tho cities. The descriptive statistics, Cronbach Alpha test, Explor- } \\
\text { atory Factor Analysis, Confirmatory Factor Analysis and Structural Equation Modelling methods } \\
\text { were used in this paper. The results indicate that KM had a positive impact on the efficiency of the } \\
\text { business organizations. The study also shows that there was a big difference on the effect of KM } \\
\text { on organizational effectiveness in terms of SMEs and large enterprises. }\end{array}$ \\
\hline
\end{tabular}

\section{Introduction}

Many business leaders believe their companies experience with the departure of key personnel at least once. Many companies make value added products but products and tangible assets are not the primary value of the firms (Probst et al., 2000). The most important thing is when some employees bring knowledge and when they leave it is not easy for companies to fill their space. Many Viet Nam organizations spend hundreds of millions Vietnamese dong each year for staff training. However, the knowledge acquired from staff training to create value may not necessarily created value-added products or services. The waste is more evident when the amount of time spent to find the actual knowledge that already exists within the organization is very large (Earley, 1994; Enz, 1986). If one organization does not know how to administer good knowledge of the company, the assets will be small and vice versa, if the knowledge is cumulative, development and good governance will help to constantly grow the companies. In other words, if the previous issues of enterprise development (businesses) depend on strong

\footnotetext{
* Corresponding author.

E-mail address: springvnh@yahoo.com (N.X.Vu) 
economic management, but now, in the knowledge economy, the existence and sustainable development of enterprises depends on all key strengths, i.e. Knowledge Management (KM).

Today, knowledge management plays an important role for the development of the companies and no organization is able to handle the day-to-day activities without knowledge management (De Long \& Fahey, 2000). More precisely, knowledge is truly the most important asset of any company. However, not all organizations have realized the significance of promoting the management of such assets sources. One of the benefits of implementing knowledge management in organizations is the positive impact it has on the effectiveness of the organization. Some studies show that there is a positive relationship between knowledge management activities to improve the effectiveness of organizations (Zaied et al., 2012); the knowledge management that affects the leadership competencies and leadership abilities directly influences the effectiveness of the organization (Addicott et al., 2006). Thus, the effective implementation of knowledge management in the enterprise will bring better efficiency for the organizations (Bloor \& Dawson, 1994; Broadbent, 1984; Broadbent \& Koenig, 1988).

In Vietnam in general, the implementation of knowledge management is still very limited, very few businesses are interested in the implementation of knowledge management in their organizations. It is worth to say that businesses do not understand clearly the magic of KM and they are not fully aware of the impact of operational knowledge management on organizational effectiveness of the businesses. In this context, recognizing fully the importance and see the positive impact of knowledge management activities for the effective organization of business is paramount. Stemming from the above issues, the authors investigate the knowledge management in businesses and education by perform an in-depth survey on Vietnam companies and universities to help Vietnam enterprises and universities to implement governance knowledge more effectively.

\section{Literature review}

Knowledge management (KM) efforts often are seen to encounter difficulties from corporate culture and, as a result, to have limited impact (De Long \& Fahey, 2000; O'Dell \& Grayson, 1998; Chatman \& Barsade, 1995; Graham, 1996). An Ernst and Young study identified culture as the biggest impediment to knowledge transfer, citing the inability to change people's behaviors as the biggest hindrance to managing knowledge (Watson, 2001). In another study of 453 firms, over half indicated that organizational culture was a major barrier to success in their knowledge management initiatives (Ruggles, 1998). The importance of culture is also evident from consulting firms such as KPMG who report that a major aspect of knowledge management initiatives involves working to shape organizational cultures that hinder their knowledge management programs (KPMG, 1998). These findings and others (Hasan \& Gould, 2001; Schultze \& Boland, 2000; Hansen et al., 1999) help to demonstrate the profound impact that culture may have some effects on knowledge management practices and plays crucial role on senior management in fostering cultures conducive to these practices (Brown \& Duguid, 2000; Davenport et al., 1998; DeLong \& Fahey, 2000; Gupta \& Govindarajan, 2000; Hargadon, 1998; KPMG, 1998). Studies on the role of culture in knowledge management have focused on such issues as the effect of organizational culture on knowledge sharing behaviors (DeLong \& Fahey, 2000; Jarvenpaa \& Staples, 2001) and the influence of culture on the capabilities provided by KM (Gold et al., 2001) as well as on the success of the KM initiative (Balthazard \& Cooke, 2003). More specifically, Balthazard and Cooke (2003) ascertained that constructive cultures (emphasizing values related to encouragement, affiliation, achievement, and self-actualization) tended to achieve greater KM success. Similarly, Gold et al. (2001) found that more supportive, encouraging organizational cultures positively influence KM infrastructure capability and resulting KM practice. Finally, Jarvenpaa and Staples (2001) determined that organizational cultures rating high in solidarity (tendency to pursue shared objectives) will result in a perception of knowledge as being owned by the organization, which, in turn, leads to greater levels of knowledge sharing. While studies have shown that culture influences knowledge management and, in particular, knowledge sharing, there is little research on the broader aspects of the nature and means through which 
culture influences the overall approach taken to knowledge management in a firm. Among the definitions of knowledge management, according to Smith (2001) "Knowledge management is a process that consists of the activities of collecting, accumulating knowledge for the organization; allocation and application of knowledge in the activities of the organization; practice sharing and protection of the rights of intellectual creation and implementation of a number of measures to motivate employees to maintain the valuable knowledge to the organization". Thus, from the above concepts it can be seen that the main activities in knowledge management include: search and accumulation, knowledge sharing within the organization, motivate employees, convert and distribute knowledge in organizations and protection of civil rights of the creator of knowledge (Nonaka, 2007).

Regarding the relationship between knowledge management and organizational effectiveness of the business, Bhatti et al. (2011) and Rasula et al. (2012) suggest that there is a relationship positive between operational knowledge management and organizational effectiveness of the business. In other words, strengthening the implementation of the operational knowledge management effectively increases the effective organization enterprise. According to Chen et al. (2009), Chen and Huang (2007) and Robinson et al. (2006) the concept of organizational effectiveness is to attract and retain employees and attract and retain customers, financial performance, innovation and organizational innovation, process handled internally.

\section{Research methods and analysis of the results}

\subsection{Data collection and methods}

Primary data used in the study were collected through direct interviews of 300 enterprises and universities in Vietnam with convenient sampling method. To increase the representation, four provinces; namely Hanoi, Danang, Ho Chi Minh and Can Tho were selected by authors that focus more on businesses and their growth rate was relatively high. Then, the authors determined the number of enterprises for interview in the province based on the characteristics of each area, such as: the number of enterprises in the province, the situation of economic development and enterprise characteristics in the areas. In addition, the number of firms interviewed in areas allocated by sector of business activity are shown in Table 1. Accordingly, field-service trade accounts for the largest percentage by the number of firms operating in this area was very large for the objective of the research. Then, based on the business listing activities in each area the authors selected businesses to interview based on the following criteria: size of the business, access to interviews, representative of the industry, and uptime of the business.

\section{Table 1}

Structure of the sample according to geographical areas and fields of activity

\begin{tabular}{|c|c|c|c|c|c|}
\hline Activities & Ha Noi & Da nang & Ho Chi Minh & Can Tho & General \\
\hline Trading - Service & 80 & 52 & 38 & 45 & 215 \\
\hline Industry - construction & 20 & 12 & 8 & 10 & 50 \\
\hline Agriculture, forestry and fisheries & 10 & 6 & 4 & 5 & 25 \\
\hline Universities & 3 & 2 & 3 & 2 & 10 \\
\hline Total & 113 & 72 & 53 & 62 & 300 \\
\hline
\end{tabular}

\subsection{The hypotheses}

Research model is built based on summarizing the theory and previous studies on the impact of knowledge management to the efficiency of the organizations and we have built two hypotheses as follows:

H1: knowledge management activities are subject to the impacts of the factors including information technology, intellectual capital of the organization and elements of the organization and strategy of the organization. 
H2: $_{2}$ The enhanced implementation of knowledge management activities has a positive impact to increase the efficiency of the business organization.

\subsection{Rating scale reliability by Cronbach's alpha}

In measuring the reliability rating of scale we have removed the observed variables with a correlation coefficient less than 0.3. Load factor coefficients of the observed variables must be greater than 0.5. However, with a sample size of $\geq 200$ the acceptable load factor is 0.4 (Hair, 2010). The criteria for selecting the scale is reliable Alpha 0.6 or higher, but preferably greater than 0.7 (Nunnally \& Bernstein, 1994). Factors affecting operations knowledge management is measured by 22 variables reflecting the impacts of information technology, elements of the organization, intellectual capital of the organization and strategy organization. The concept of knowledge management activities are measured by 5 observed variables reflecting the implementation of knowledge management activities. Concept organizational effectiveness is measured by five key interest groups and interest groups 5 are measured by 27 variables observed reflects the increasing level 5 group benefits. Result analysis shows Cronbach's alpha coefficients of the scales are greater than 0.7 and a correlation coefficient of total variation of the observed variables are greater than 0.3 , which indicate the measurement variation is good (Nunnally \& Bernstein, 1994).

\subsection{Analysis factors discover (EFA)}

\section{EFA scale factors affecting operations knowledge management}

Inspection KMO and Bartlett in EFA were used to examine the relationships between variables and the appropriateness of the classification model factors area, if $0.5<\mathrm{KMO}<1$, the factor analysis is appropriate and, if we test Bartlett with statistical significance ( $\mathrm{Sig} \leq 0.05)$, then the observed variables are correlated with each other in the overall.

The results of the 1st EFA group criticized include 5 factors on the total variance extracted which is $57.56 \%$ ( $>50 \%)$ and unsatisfactory. However, variable coefficient and load factor are 0.284 and 0.323 respectively and they are smaller 0.4 which should be excluded from the scale.

Checking the condition of the EFA yields $\mathrm{KMO}=(0.5<0.895<1)$ which is satisfactory and p-value $=$ $0.00<0.05$ shows interrelated variables and data conform to the CFA. Results of EFA group criticized four factors with $55.10 \%$ of the total variance extracted. Because of the disturbance, rename variables observed between factors initial assumptions should be four groups of factors behind EFA: 1 - sources of knowledge of the organization, 2 - Strategy and characteristics of the organization, 3 - The management style and motivate employees, 4 - information technology.

\section{EFA scale knowledge management}

Results of EFA extract is 1 factor to total variance extract reached 56.19\% ( $>50 \%)$ unsatisfactory. Load factor coefficients of the variables are greater than 0.4 observed. $\mathrm{KMO}=0.821(>0.5$ and $<1)$ satisfactory and $p$ value $=0.00<0.05$ indicate the variables are correlated with each other and consistent data to the CFA.

\section{EFA scale organizational efficiency}

Results 1 extract is 4 times EFA group with interests total variance extracted is $56.97 \%$ ( $>50 \%$ ) which is unsatisfactory. Here, variable coefficient THKH7 load factor is less than $0.4(0.363)$ which should be removed from the scale. $\mathrm{KMO}=0.936$ with $\mathrm{p}$-value $=0.00<0.05$ indicates the variables are correlated with each other and consistent data to the CFA. Due to the observed disturbance, variables between factors should assume initial four EFA group following factors were renamed: 1. Financial performance, 2 - Improve the organization, 3 - Attract, keep customer foot, 4 - Attracting, retaining employees. 
Results of Chi-squared test for the model with the critical $\mathrm{p}$-value $=0.000<0.05$ yields Chi-square criteria $/ \mathrm{df}=1,511(<2)$, TLI $=0.902$ values and CFI $=.909$ are greater than 0.9 and RMSEA $=0.049<0.08$. Thus, the indicators are satisfactory; the model fits the data market. The normalized weights are not statistically significant ( $p$-value $<0.05$ ) and normalized weights are $>0.5$ to achieve value scale convergence. Besides, the testing results show that the values are $p$-value $<0.05$ with correlation coefficient for each pair of concepts $<1$ at $95 \%$ confidence level.

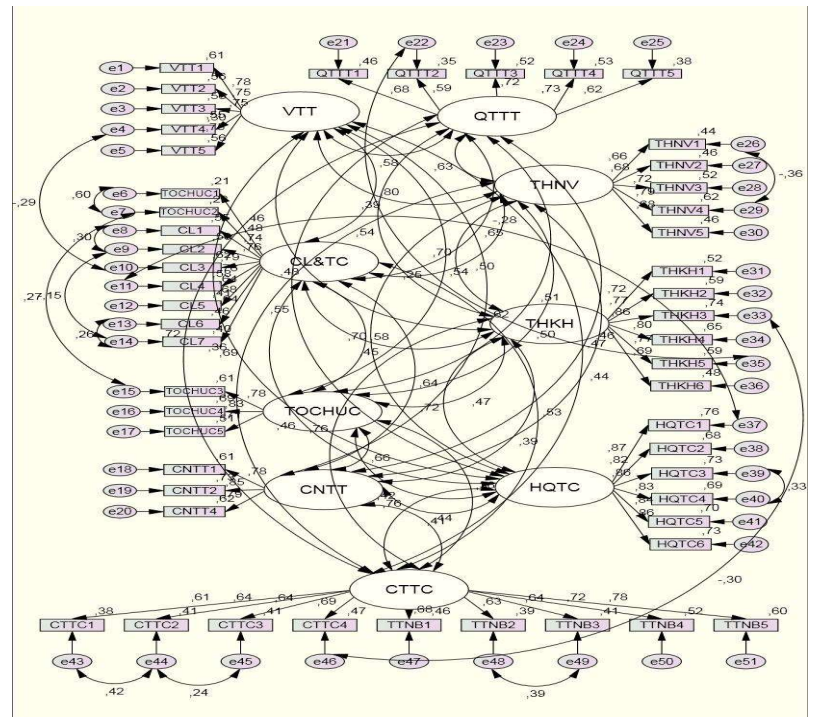

Fig. 1. Results of the CFA model tipping

Chi-square $=1773.879 ; \mathrm{df}=1174 ; \mathrm{p}=0.000 ;$

Chi-square $/ \mathrm{df}=1,511 ; \mathrm{GFI}=0.773 ; \mathrm{TLI}=0.902 ; \mathrm{CFI}=0.909 ; \mathrm{RMSEA}=0.049$

VTT: intellectual capital of the organization; THKH: attracting and retaining customers; CTTC: organizational improvement; HQTC: financial efficiency; CL \& TC: War strategic, organizational characteristics; QTTT: active knowledge management; THNV: attracting and retaining staff, the organization: leadership style, motivate employees

(Source: the results of data processing are direct inspection of 300 enterprises\& universities of the group studies, 20162017)

Testing the impact of management knowledge to organizational efficiency of Vietnam companies and universities

\section{Inspection theoretical model by SEM}

Results are not standardized estimates of the key parameters and show Circle relations theories are statistically significant ( $p$-value $<0.05$ ): knowledge Management - Strategies and characteristics of organizations (0.000), second tri Administration c - leadership style and motivate employees (0.017) and Knowledge Management - Effective organizations (0.000). Moreover, the weighted normalized have positive signs indicating that these factors have strong impacts to the operational knowledge management with an influence respectively 0.566 and 0.196 , and operational knowledge management has a positive impact on the efficiency of the business organization with an influence of 0.726 . Ability to explain the dependent variable in the model is also quite high, namely, knowledge management is explained at $48.5 \%$ by the above factors and organizational effectiveness is explained by operational management at $52.7 \%$ knowledge. 


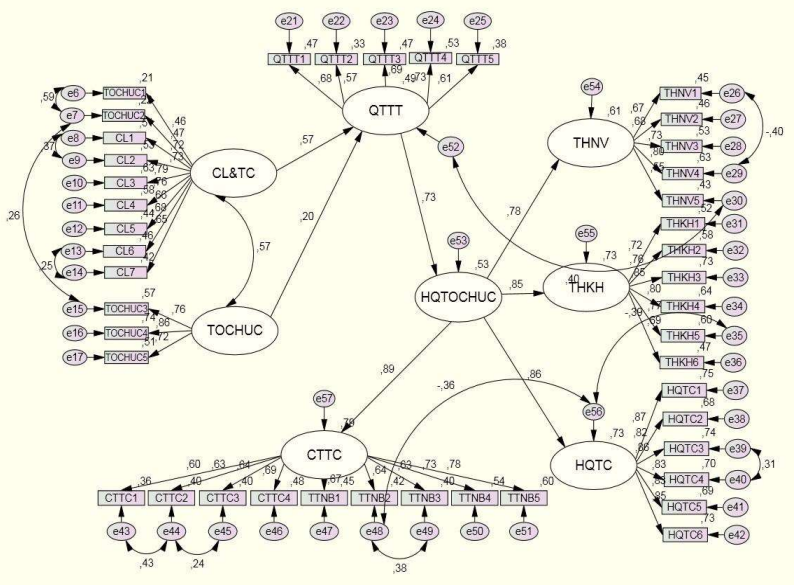

Chi-square $=1357.777 ; \mathrm{df}=840 ; \mathrm{p}=0.000 ;$

Chi-square $/ \mathrm{df}=1.616 ; \mathrm{GFI}=0.787 ; \mathrm{TLI}=0.900 ; \mathrm{CFI}=0.907 ; \mathrm{RMSEA}=0.054$;

Fig. 2. Output of the second SEM model

(Source: the results of data processing are direct inspection of 300 enterprises \& universities of the group studies, 20162017)

Testing the differences for the impact of knowledge management to organizational effectiveness among different types of enterprises

Table 2 presents the results of Chi-Square test.

\section{Table 2}

The results of the Chi-Square test

\begin{tabular}{lccc}
\hline & Chi-Square & df & P-Value \\
\hline Variable model & 2922.716 & 1680 & $0.016^{* *}$ \\
Invariable model & 2912.160 & 1685 & \\
\hline Difference & 9.342 & 3 & \\
\hline (Source: the results of data processing are direct inspection of 300 enterprises\& & universities of the group studies, 2016-2017)
\end{tabular}

\section{Table 3}

The importance of standardization in the model variability

\begin{tabular}{llcc}
\hline Relationship & \multicolumn{2}{c}{ Estimate } \\
\cline { 2 - 4 } & SMEs & LARGE \\
\hline Knowledge Management & $\leftarrow$ Strategic and organizational characteristics & 0.571 & 0.421 \\
Knowledge Management & $\leftarrow$ Style consulate direct and motivate employees & 0.242 & 0.145 \\
Effective organization & $\leftarrow$ Knowledge Management & 0.686 & 0.801 \\
\hline
\end{tabular}

$\mathrm{R}^{2} \mathrm{KM} \mathrm{SMEs}=53.9 \% ; \mathrm{R}^{2}$ EO SMEs $=47.0 \% ; \mathrm{R} 2 \mathrm{KM}$ Large $=23.6 \% ; \mathrm{R}^{2}$ EO Large $=64.2 \%$

(Source: the results of data processing are direct inspection of 300 enterprises\& universities of the group studies, 2016-2017)

The results of Table 3 indicate that three factors; namely the strategic and characteristics of the organization and leadership styles and motivating staff in positively influence knowledge management and knowledge management maintains similar impact on the efficiency of the business organizations in both types of businesses. However, the impacts of these factors to the operation of knowledge management are different. According to the analysis results, the factors of strategic and characteristics of the organization and leadership style and motivate employees have stronger impacts to operational knowledge management in SMEs. By contrast, for big businesses, the impact of knowledge management activities to the organizational effectiveness is stronger in big businesses, this result is entirely consistent with the fact that, for large companies outside the strategic factors and leadership styles, the intellectual resources and financial resources have great influences on the management activities of knowledge. On the other 
hand, large enterprises invest more on active knowledge management due to the considerable resources they should consume in large enterprises and maintain a stronger impact on organizational effectiveness enterprise than SMEs.

\section{Some solutions to improve performance knowledge management in Vietnam companies and universities}

\subsection{Recommendations for Vietnamese companies}

First, businesses are looking for understanding the importance and the impact of the operational knowledge management for the efficiency of the enterprise. Thus, they must be after clear orientation to learn techniques on how to implement the activities of their enterprises through learning from the mass media such as TV, internet, social networks, popular newspapers, magazines, journals, etc. Besides, leaders of enterprises should strengthen exchange information and learn the implementation of knowledge management from their partners, especially from competitors. Involvement in conferences or short-term training courses related to knowledge management issues helps them apply their own businesses.

Second, they need to protect the rights of creators of valuable knowledge and to encourage the creation of new knowledge for the enterprises. Businesses need to take measures to protect what employees in their organizations create and to register their copyrights or receive appropriate certificates from the competent authorities to protect the rights of the creators of the knowledge. Besides, enterprises should strengthen the search and cumulative knowledge resources for businesses.

Third, organizations need to build strategies consistent with the sustainable development goals of their organization. Businesses need to build knowledge management strategies based on the objectives and strategies of their organizations. Also, on the issue of financial firms, they need to establish a special fund for the implementation of knowledge management within their organizations. Businesses need to invest in long-term operations, especially large enterprises with strong financial resources. However, for small and medium-sized enterprises, this is not a simple task and they do not have enough financial resources to implement all the activities associated with knowledge management, so enterprises need to determine whether or not the activities are necessary and consistent with the actual circumstances of the enterprises in order to balance the resources of their organizations and take their pick activities accordingly.

Fourth, Organizations need to handle leadership style and to motivate staff also greatly to influence the knowledge management activities. Therefore, the leaders of enterprises should have the attitude, behavior appropriate to each employee within their organizations to create a good working environment, enhance the collaboration of employees within the organization.

\subsection{Recommendations for Vietnamese Universities}

We find that faculty plays a central role of the knowledge management at university and for the university development, it is necessary to enhance the role and the significance of the knowledge management. In order to develop the universities in the Southeast Asian region, the directors of Vietnam universities need to implement a number of measures as follows:

First, they need to enhance the role of the department in supervising professional capacities of the faculty. Department plays an important role in assessing the qualifications of the faculty, departments should have the right to decide and exclude poor faculties from the others.

Secondly, the subject should play an essential role for the calculation of financial revenues and expenditures related to the field of professional responsibility. Faculty payment should be allocated based on the subjects, which could be distributed to department faculties. 
Thirdly, the department should work closely with faculty leaders to attract funding for the department, faculty/institute in particular and the school in general. Sources of Alumni force have important implications for the development of the resources for research and scientific development.

Fourth, the subject should be autonomous in scientific research and application deployment results in practices.

Fifth, there is a need to coordinate the departments with each other and engage them in scientific studies and technology transfer. The policies should be used to strengthen the intellectual resources of professor's experience with long seniority in teaching and scientific research. Because it is a source of valuable knowledge, experience contributed greatly for the development of the universities. The fact that creating brand and values of the university is not a modern infrastructure, which is knowledge, knowledge of the professors in the department's specialized schools, this knowledge should be inherited and developed in conjunction with process innovation universities and regional integration in the world. In addition, knowledge management is not only important in the corporate sector but also at the universities. At the same time, the development of information systems to support knowledge management is important. This is the most effective tool to minimize the risk of causing brain drain.

\section{Conclusion}

A large number of enterprises and universities in Vietnam are not fully aware of the activities and knowledge management in their organizations. Especially understanding the importance and practical benefits that the implementation of knowledge management brings has shown that theoretical models of knowledge management could be affected by the factors of strategic and organizational characteristics and leadership styles and employees' motivation. Owning strategic factors and characteristics of organizations have great influence on the knowledge management activities within the organizations. Knowledge management has a positive impact on the efficiency of the business organizations. On the other hand, the study has also shown that there was a big difference on the effect of knowledge management on organizational effectiveness in terms of SMEs and large enterprises. Specifically, knowledge management activities in large enterprises had stronger impacts on organizational efficiency than SMEs did. In addition, for large enterprises, the impacts of strategic factors and characteristics of the organizations and leadership style factors and employees' motivation were lower than SMEs. Any organization, whether governmental, non-governmental organizations or businesses will also be shaped by different individuals. Each individual has different background knowledge, qualifications, abilities, experience, etc. Knowledge management will help individuals communicate, exchange and share knowledge better. In particular, knowledge management will help leaders; policy makers make decisions, more effective policies for their organizations.

In today's age, knowledge is power and if we capture the knowledge management tools we may take advantage of its advantageous to empower the organizations through systematic procedures. Culture, habits, knowledge sharing responsibility play important role for knowledge management. It is important for people to see how they are responsible for sharing their knowledge and ensure that everyone receives the knowledge from the others appropriately. The individuals of the organizations should also be aware that knowledge in the head is not only personal property but also it is a collective knowledge. Knowledge Management is also inherited a lot from the achievements of information technology (IT). The system of internal communication or external information of many businesses relies heavily on IT. If conditions permit, the organization/ enterprise should build a portal for knowledge management accordingly. In Vietnam many units started to cope with knowledge management and, at the same time, we have leant some lessons from the international experiences. Thus, there is a need to study and have an accurate assessment of system knowledge and the knowledge capacity.

In summary, we suggest the solutions for Viet Nam companies and universities as follows: 
- The policies and procedures should be knowledge documented to avoid unnecessary misunderstandings and easy to detect errors occurring at any stage.

- Develop a unified documentation system to capture knowledge.

- Focus on training and knowledge transfer. Cultural sharing is essential in training activities. Those experiences should be encouraged to see and be responsible for sharing and guiding less experienced ones. In addition, organizations can take advantage of the knowledge of other organizations if such knowledge is not used properly, but to know how to protect a specific knowledge for their organizations.

- Continually update new information and learn from the work accomplished and the experience of other organizations.

- Focus on the human factor. Humans can create new knowledge and new people only able to use that knowledge to create more knowledge. Organizations should have policies to recruit young workforce, enabling people with experience working with new people.

- IT applications. IT plays a supporting role, making the sharing; storing, updating and using knowledge is made easier

Finally, the hardest thing to implement KM is probably to make an awareness of the problem. Only when the knowledge is recognized as an asset, the new leaders of the organizations are aware of the protection, preservation, investment and embellished them into greater wealth.

\section{References}

Addicott, R., McGivern, G., \& Ferlie, E. (2006). Networks, organizational learning and knowledge management: NHS cancer networks. Public Money and Management, 26(2), 87-94.

Balthazard, P. A., \& Cooke, R. A. (2004, January). Organizational culture and knowledge management success: assessing the behavior-performance continuum. In 37th Annual Hawaii International Conference on System Sciences, 2004. Proceedings of the (pp. 10-pp). IEEE.

Bhatti, W. A., Zaheer, A., \& Rehman, K. U. (2011). The effect of knowledge management practices on organizational performance: A conceptual study. African Journal of Business Management, 5(7), 2847-2853.

Bloor, G., \& Dawson, P. (1994). Understanding professional culture in organizational context. Organization studies, 15(2), 275-295.

Broadbent, M., \& Koenig, M. E. (1988). Information and information technology management. Annual review of information science and technology, 23, 237-270.

Broadbent, M. (1984). Information management and educational pluralism. Education for Information, 2(3), 209-227.

Brown, J. S., \& Duguid, P. (2000). Balancing act: How to capture knowledge without killing it. Harvard business review, 78(3), 73-80.

Chatman, J. A., \& Barsade, S. G. (1995). Personality, organizational culture, and cooperation: Evidence from a business simulation. Administrative Science Quarterly, 423-443.

Chen, C. J., \& Huang, J. W. (2007). How organizational climate and structure affect knowledge management-The social interaction perspective. International journal of information management, 27(2), 104-118.

Chen, M. Y., Huang, M. J., \& Cheng, Y. C. (2009). Measuring knowledge management performance using a competitive perspective: An empirical study. Expert systems with applications, 36(4), 84498459.

Davenport, T. H., De Long, D. W., \& Beers, M. C. (1998). Successful knowledge management projects. Sloan management review, 39(2), 43-57.

De Long, D. W., \& Fahey, L. (2000). Diagnosing cultural barriers to knowledge management. Academy of Management Perspectives, 14(4), 113-127. 
Earley, P. C. (1994). Self or group? Cultural effects of training on self-efficacy and performance. Administrative science quarterly, 39(1).

Enz, C. A. (1986). Power and shared values in the corporate culture (Vol. 90). Umi Research Pr.

Graham, A. (1996). The learning organisation: Managing knowledge for business success. Economist Intelligence Unit.

Gold, A. H., Malhotra, A., \& Segars, A. H. (2001). Knowledge management: An organizational capabilities perspective. Journal of management information systems, 18(1), 185-214.

Gupta, A. K., \& Govindarajan, V. (2000). Knowledge management's social dimension: Lessons from Nucor Steel. MIT Sloan Management Review, 42(1), 71.

Hansen, M. T., Nohria, N., \& Tierney, T. (1999). What's your strategy for managing knowledge. The knowledge management yearbook 2000-2001, 77(2), 106-116.

Hasan, H., \& Gould, E. (2001). Support for the sense-making activity of managers. Decision Support Systems, 31(1), 71-86.

Hargadon, A. B. (1998). Firms as knowledge brokers: Lessons in pursuing continuous innovation. California Management Review, 40(3), 209-227.

Jarvenpaa, S. L., \& Staples, D. S. (2001). Exploring perceptions of organizational ownership of information and expertise. Journal of management information systems, 18(1), 151-183.

Nonaka, I. (2007). The knowledge-creating company. Harvard Business Review, 85(7-8).

Nunnally, J. C., \& Bernstein, I. H. (1994). Psychological theory. New York, NY: MacGraw-Hill, 131147.

O'dell, C., \& Grayson, C. J. (1998). If only we knew what we know: Identification and transfer of internal best practices. California management review, 40(3), 154-174.

Probst, G., Romhardt, K., \& Raub, S. (2000). Managing knowledge: Building blocks for success. J. Wiley.

Robinson, H. S., Anumba, C. J., Carrillo, P. M., \& Al-Ghassani, A. M. (2006). STEPS: a knowledge management maturity roadmap for corporate sustainability. Business Process Management Journal, 12(6), 793-808.

Ruggles, R. (1998). The state of the notion: knowledge management in practice. California management review, 40(3), 80-89.

Rasula, J., Vuksic, V. B., \& Stemberger, M. I. (2012). The impact of knowledge management on organisational performance. Economic and Business Review for Central and South-Eastern Europe, 14(2), 147.

Schultze, U., \& Boland Jr, R. J. (2000). Knowledge management technology and the reproduction of knowledge work practices. The Journal of Strategic Information Systems, 9(2-3), 193-212.

Smith, E. A. (2001). The role of tacit and explicit knowledge in the workplace. Journal of knowledge Management, 5(4), 311-321.

Watson, I. (2001, May). Knowledge Management and Case-Based Reasoning: A Perfect Match?. In FLAIRS Conference(pp. 118-122).

Zaied, A. N. H., Hussein, G. S., \& Hassan, M. M. (2012). The role of knowledge management in enhancing organizational performance. International Journal of Information Engineering and Electronic Business, 4(5), 27.

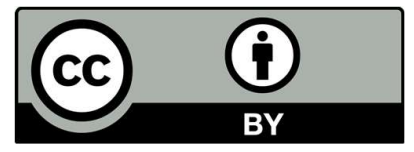

(C) 2019 by the authors; licensee Growing Science, Canada. This is an open access article distributed under the terms and conditions of the Creative Commons Attribution (CCBY) license (http://creativecommons.org/licenses/by/4.0/). 